\title{
Betaine alleviates high glucose-induced mesangial cell proliferation by inhibiting cell proliferation and extracellular matrix deposition via the AKT/ERK1/2/p38 MAPK pathway
}

\author{
XIANHUI LI ${ }^{1}$, LI WANG ${ }^{2}$ and HUINING MA ${ }^{3}$ \\ ${ }^{1}$ Department of Traditional Chinese Medicine, Tianjin Key Laboratory of Artificial Cell, \\ Tianjin Institute of Hepatobiliary Disease, Artificial Cell Engineering Technology Research Center of Public Health Ministry, \\ Third Central Hospital of Tianjin, Tianjin 300170; ${ }^{2}$ Department of Basic Medicine, Tianjin Medical College, Tianjin 300222; \\ ${ }^{3}$ Department of Traditional Chinese Medicine, Tianjin 4th Centre Hospital, Tianjin 300140, P.R. China
}

Received October 9, 2018; Accepted May 14, 2019

DOI: $10.3892 / \mathrm{mmr} .2019 .10391$

\begin{abstract}
Diabetic nephropathy (DN) is a major cause of chronic renal failure in diabetic patients worldwide. Betaine, a zwitterionic quaternary ammonium salt compound, is involved in numerous biological processes. The present study aimed to investigate the effects of betaine on mouse mesangial cells (MMCs) cultured under high glucose (HG) conditions and its underlying mechanisms. MMCs were treated with betaine under HG conditions. Cell proliferation and the cell cycle distribution were investigated with an MTT assay and flow cytometry, respectively. Western blotting and reverse transcription-quantitative polymerase chain reaction analyses were applied to respectively determine protein and mRNA expression levels. The results suggested that betaine decreased cell proliferation in a dose-dependent manner, while G1-phase arrest was significantly induced in MMCs. Compared with the control group, the expression levels of p21 and p27 decreased under HG conditions, but were reversed by betaine. Furthermore, the expression levels of fibronectin and type IV collagen were significantly decreased in cells treated with betaine compared with the HG group. Additionally, betaine decreased the phosphorylation of Akt, extracellular-signal-regulated kinase (Erk)1/2 and p38 mitogen-activated protein kinase (MAPK), but was enhanced under HG conditions. Overall, the results of the present study indicated that betaine serves a protective role in HG-induced MMCs by inhibiting cell proliferation and
\end{abstract}

Correspondence to: Dr Xianhui Li, Department of Traditional Chinese Medicine, Tianjin Key Laboratory of Artificial Cell, Tianjin Institute of Hepatobiliary Disease, Artificial Cell Engineering Technology Research Center of Public Health Ministry, Third Central Hospital of Tianjin, 83 Jintang Road, Hedong, Tianjin 300170, P.R. China

E-mail: 1xh1808@sina.com

Key words: diabetic nephropathy, betaine, cell proliferation, extracellular matrix, mice mesangial cells extracellular matrix deposition via regulating regulation of the Akt/Erk1/2/p38 MAPK signaling pathway.

\section{Introduction}

Diabetic nephropathy (DN), as a diabetic microvascular complication, is mainly responsible for chronic renal failure in diabetic patients worldwide (1,2). Mesangial cell abnormalities and the deposition of extracellular matrix (ECM) proteins, such as fibronectin and collagen, are the main pathological hallmarks of DN (3). It has been reported that the proliferation of mesangial cells serves a vital role in the initiation and development of DN (4). Under high glucose (HG) conditions, glomerular mesangial cell dysfunction, followed by imbalances in ECM protein secretion and degradation, result in the deposition of ECM proteins in the mesangium and basement membrane regions, which leads to pathological changes in glomerular morphology, structure and function, and the development of glomerulosclerosis $(5,6)$. At present, various factors have been identified to be important in the development of DN; however, the underlying mechanisms remain unclear.

Betaine, a neutral zwitterionic compound, is a naturally occurring byproduct of sugar beet refinement, which is extracted from molasses. Betaine has been detected in microorganisms, animals and plants, including wheat, spinach, shellfish and shrimp (7). This compound serves dual roles in human physiology, functioning as an osmolyte and as a methyl donor in transmethylation. As an osmolyte, in order to maintain fluid balance, betaine can protect cells, enzymes and proteins from environmental stresses, including high salinity and extreme temperatures. As a methyl donor, betaine is involved in the methionine cycle in the kidneys and liver in humans (8). In addition, betaine participates in a variety of biological processes. Betaine was reported to suppress prostaglandin synthesis in rat liver macrophages, thus modulating tumor necrosis factor- $\alpha$ secretion and reversing the inhibitory effects of acetaldehyde on the interferon signaling pathway $(9,10)$. Additionally, as a natural food additive, betaine can induce an autoimmune response to regulate the fat:lean mass ratio and the neuro-endocrine system (11). 
Patients with inflammatory bowel disease exhibit notable declines of betaine in urine, which suggests that betaine may be involved in the modulation of immune responses (12). Furthermore, it has been shown that betaine decreased serum glucose and renal oxidative stress in diabetic rats (13). Thus, we speculated that betaine may be an effective agent for the treatment of diabetes and its associated complications. The present study aimed to investigate the effects of betaine on the development of $\mathrm{DN}$, and to determine the underlying potential mechanisms.

\section{Materials and methods}

Cell culture. Kidneys from mice were removed in a sterile manner in accordance with the guidelines set by the National Institutes of Health Guide for the Care and Use of Laboratory Animals (14). Briefly, 10 mice aged 5-6 weeks old and weighing 18-20 g were purchased form the Experimental Animal Center of Shanxi Medical University. These mice were maintained under standard conditions (temperature $22^{\circ} \mathrm{C}, 12$-h light-dark cycle) and given free access to water and a standard diet. The present study was approved by Institutional Animal Care and Use Committee of Tianjin Third Central Hospital. Mouse mesangial cells (MMCs) were extracted from kidneys and cultured as previously described (15). MMCs were cultured in RPMI-1640 medium (Gibco; Thermo Fisher Scientific, Inc.) containing HG (30 mM D-glucose) or with normal glucose levels $(5.5 \mathrm{mM}$ D-glucose), $10 \%$ fetal bovine serum (Gibco; Thermo Fisher Scientific, Inc.), and a $1 \%$ penicillin and streptomycin solution (Sigma-Aldrich; Merck KGaA) for $48 \mathrm{~h}$ in a humidified incubator with $5 \% \mathrm{CO}_{2}$ at $37^{\circ} \mathrm{C}$.

Cell treatment. MMCs were plated at a density of $5 \times 10^{4}$ cells/well $24 \mathrm{~h}$ prior to treatment. Betaine $(1,5$ and $10 \mu \mathrm{M}$ ) and $100 \mathrm{mM}$ metformin (Squibb Pharmaceutical Co., Ltd.) were respectively added to the cells and incubated for $48 \mathrm{~h}$ at $37^{\circ} \mathrm{C}$ under $\mathrm{HG}$ conditions (30 mM D-glucose). Cells without any treatment were regarded as the normal control group, while cells treated with metformin alone were regarded as the positive control group.

MTT assay. Cell proliferation was determined by an MTT assay. Briefly, cells at a density of $1.0 \times 10^{6}$ were seeded into a 96-well culture plate. Following various treatment for $48 \mathrm{~h}$ at $37^{\circ} \mathrm{C}$, cells were incubated in $0.2 \mathrm{mg} / \mathrm{ml} \mathrm{MTT} \mathrm{solution}$ (Amresco LLC) for $4 \mathrm{~h}$ at $37^{\circ} \mathrm{C}$. Then, dimethyl sulfoxide was added to each well to dissolve the formazan crystals and the optical density at $490 \mathrm{~nm}$ was detected using a Synergy ${ }^{\mathrm{TM}}$ Multi-Mode Microplate Reader (Bio-Tek Instruments, Inc.).

Cell cycle assay. For cell cycle analysis, cells were harvested after treatment for $48 \mathrm{~h}$ at a initial density of $6.0 \times 10^{5}$ cells/well in 6-well plates, washed with PBS, and then fixed with $70 \%$ ethanol at $4^{\circ} \mathrm{C}$ overnight. Subsequently, MMCs were incubated with RNase A (50 $\mu \mathrm{g} / \mathrm{ml}$; Sigma-Aldrich; Merck KGaA) and propidium iodide (50 $\mu \mathrm{g} / \mathrm{ml}$; Sigma-Aldrich; Merck KGaA) at $4^{\circ} \mathrm{C}$ for $30 \mathrm{~min}$. Finally, the cell cycle was analyzed with a flow cytometer (FACSCanto II; BD Biosciences) and CellQuest software (BD Biosciences).
Western blot analysis. For western blot analysis, cells were lysed using lysis buffer (Cell Signaling Technology, Inc.). Total protein was extracted from cells and its concentration was measured with a BCA protein assay kit (Thermo Fisher Scientific, Inc.). Samples were subjected to $11 \%$ SDS-PAGE and then transferred to polyvinylidene difluoride membranes. The membranes were incubated with primary antibodies $(1: 1,000)$ against fibronectin (ab2413, Abcam), type IV collagen (ab6586, Abcam), p21 (cat. no. 2947, Cell Signaling Technology, Inc.), p27 (cat. no. 3686, Cell Signaling Technology, Inc.), phosphorylated (p)-Akt (cat. no. 9614, Cell Signaling Technology, Inc.), Akt (cat. no. 9272, Cell Signaling Technology, Inc.), p-extracellular-signal-regulated kinase (Erk)1/2 (cat. no. 3510, Cell Signaling Technology, Inc.), Erk1/2 (cat. no. 4695, Cell Signaling Technology, Inc.), p-p38 mitogen-activated protein kinase (MAPK; cat. no. 4511, Cell Signaling Technology, Inc.), p38 MAPK (cat. no. 8690, Cell Signaling Technology Inc.) and GAPDH (cat. no. 5174, Cell Signaling Technology, Inc.) overnight at $4^{\circ} \mathrm{C}$ after blocking with $5 \%$ non-fat milk at room temperature for $2 \mathrm{~h}$. Subsequently, the membranes were incubated with corresponding horseradish peroxidase-conjugated secondary antibodies (Santa Cruz Biotechnology) at room temperature for $2 \mathrm{~h}$. An enhanced chemiluminescence detection system (SuperSignal West Dura Extended Duration Substrate, Pierce; Thermo Fisher Scientific, Inc.) was used to determine protein expression and the Quantity One analysis system version 4.6 (Bio-Rad Laboratories, Inc.) was used for the quantification of protein expression.

Reverse transcription-quantitative polymerase chain reaction $(R T-q P C R)$. Total RNA was extracted from MMCs using TRIzol $^{\circledR}$ reagent (Invitrogen; Thermo Fisher Scientific, Inc.) according to the manufacturer's protocols. Complementary DNA was synthetized at $37^{\circ} \mathrm{C}$ for $15 \mathrm{~min}$ and $85^{\circ} \mathrm{C}$ for $5 \mathrm{sec}$ using a PrimeScript RT Reagent kit (Takara Biotechnology Co., Ltd.) and analyzed with a TaqMan Universal PCR Master Mix kit (Thermo Fisher Scientific, Inc.) under the thermocycling conditions: initial denaturation at $95^{\circ} \mathrm{C}$ for $5 \mathrm{~min}$, followed by 40 cycles of $95^{\circ} \mathrm{C}$ for $10 \mathrm{sec}$ and $60^{\circ} \mathrm{C}$ for $30 \mathrm{sec}$. The following primer pairs were used for PCR amplification: Fibronectin, forward 5'-GCAGTGACCACCATTCCTG-3', reverse, 5'-GGT AGCCAGTGAGCTGAACAC-3'; type IV collagen, forward 5'-TCCTTGTGACCAGGCATAGT-3', reverse, 5'-TTGAAC ATCTCGCTCCTCTC-3'; and GAPDH, forward: 5'-ATC CCATCACCATCTTCCAG-3', reverse, 5'-CCATCACGCACA GTTTCC-3'. GAPDH was used as an internal control. For relative gene expression quantification, the $2^{-\Delta \Delta \mathrm{Cq}}$ method was employed (16).

Statistical analysis. All experiments were repeated three times. Data were expressed as the mean \pm standard deviation. SPSS 17.0 statistical software (SPSS, Inc.) was used for all statistical analyses. One-way analysis of variance followed by a Tukey's test was used for comparisons between groups. $\mathrm{P}<0.05$ was considered to indicate a statistically significant difference.

\section{Results}

Betaine inhibits the proliferative ability of MMCs via G1-phase arrest. The effects of betaine on the growth of MMCs was 


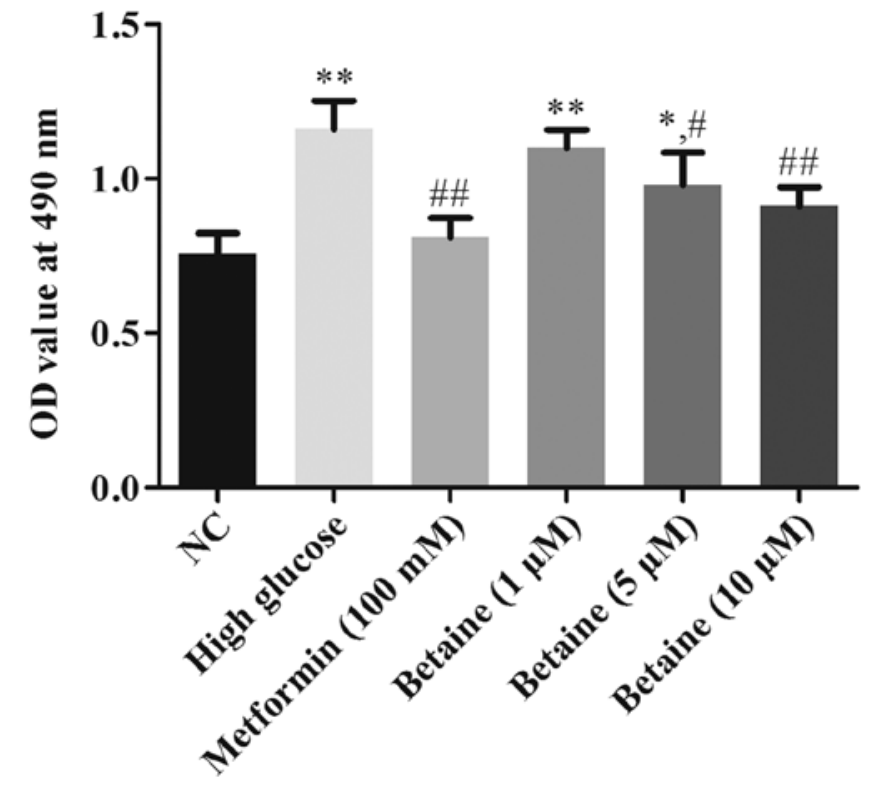

Figure 1. Betaine suppresses the proliferative ability of MMCs. Following treatment, the proliferative ability of MMCs was detected via an MTT assay. Data were expressed as the mean \pm standard deviation. ${ }^{*} \mathrm{P}<0.05,{ }^{* *} \mathrm{P}<0.01$ vs. $\mathrm{NC} ;{ }^{\#} \mathrm{P}<0.05,{ }^{\# \prime} \mathrm{P}<0.01$ vs. High glucose. MMCs, mouse mesangial cells; $\mathrm{NC}$, negative control; OD, optical density.

determined by an MTT assay. Compared with the control group, the proliferative ability of MMCs was significantly enhanced under HG conditions. Betaine treatment inhibited MMC proliferation in a dose-dependent manner. Metformin significantly repressed MMCs proliferation compared with HG treatment (Fig. 1).

As presented in Fig. 2A, compared with the control group, HG significantly reduced the proportion of cells in G1 phase, while betaine treatment induced G1-phase arrest of MMCs in a dose-dependent manner. Compared with the cells treated with $\mathrm{HG}$, the abundance of G1 phase cells significantly increased in MMCs treated with metformin. In addition, the protein expression levels of p21 and p27 were significantly decreased in MMCs treated with $\mathrm{HG}$ compared with control cells, while betaine treatment increased protein p21 and p27 protein expression in MMCs in a dose-dependent manner. Furthermore, a significant increase in the expression of the aforementioned proteins was reported following treatment with metformin compared with the HG conditions (Fig. 2B).

Betaine prevents ECM deposition in MMCs. To investigate the effects of betaine on ECM deposition in MMCs, the expression levels of ECM proteins, including fibronectin and type IV collagen, were determined. As presented in Fig. 3, the protein and mRNA expression levels of fibronectin and type IV collagen were significantly increased in MMCs treated with HG compared with the control cells; betaine treatment decreased the levels of fibronectin and type IV collagen in MMCs in a dose-dependent manner. Additionally, metformin significantly inhibited fibronectin and type IV collagen expression in MMCs compared with the HG conditions (Fig. 3). These results suggested that betaine could prevent ECM deposition induced by HG.
Betaine prevents the activation of Akt, Erk1/2 and p38. To explore the underlying mechanism of the effects of betaine on MMCs, the Akt and MAPK signaling pathways were analyzed. As presented in Fig. 4, the protein expression levels of p-Akt, p-Erk1/2 and p-p38 were significantly increased in MMCs treated with HG compared with control cells. Betaine treatment decreased the levels of $\mathrm{p}-\mathrm{Akt}$, p-Erk1/2 and p-p38 in MMCs in a dose-dependent manner. On the contrary, metformin significantly inhibited p-Akt, p-Erk1/2 and p-p38 protein expression in MMCs compared with the HG conditions (Fig. 4). These results indicated that betaine might exert its functions through the Akt and MAPK signaling pathway.

\section{Discussion}

In the present study, betaine inhibited cell proliferation, induced G1-phase arrest and reduced ECM deposition in MMCs, possibly via suppression of the Akt/Erk1/2/p38 MAPK signaling pathway. The results revealed that betaine may be a promising therapeutic agent for the treatment of DN.

$\mathrm{DN}$ is considered as one of the major microvascular complication of diabetes; $\sim 50 \%$ of diabetes cases exhibit DN, which is mainly responsible for end-stage renal disease (17). As DN poses great social and economic burden to individuals, families and society, it is a major public health problem worldwide (18). In China, the proportion of patients with end-stage renal disease caused by DN is increasing every year (19); however, the pathogenesis of DN is markedly complicated and its mechanism has not yet been fully elucidated. As the pathogenesis of DN involves in various bioactive compounds and several signaling pathways, effective preventative and treatment measures are required. Thus, exploring the pathogenesis of DN and identifying potential treatment methods to delay the progression of DN have important social and economic value.

Betaine, a methyl donor, has been reported to possess various physiological and pharmacological functions $(20,21)$. Betaine hydrochloride can be used for the prevention and therapy of atherosclerosis, liver disease gastric acid deficiency and rheumatism (22-27). Betaine possesses notable medicinal value and has broad applications; however, few studies have investigated the effects of betaine on DN. Thus, the current study aimed to investigate the effects and possible mechanism of betaine on HG-induced MMCs. Mesangial cell abnormalities and ECM deposition are pathological hallmarks of DN (6). Various studies have demonstrated that mesangial cell proliferation is crucial in the occurrence and evolvement of DN $(6,28)$. Our findings demonstrated that betaine and metformin inhibited cell proliferation, induced G1-phase arrest and prevented ECM deposition in MMCs.

In addition, the Akt, Erk1/2 and p38 MAPK signaling pathways were determined to be involved in the mechanism underlying the effects of betaine on MMCs. Akt, is a serine/threonine protein kinase reported to be anti-apoptotic and one of the main downstream targets of the phosphatidylinositol (3,4,5)-trisphosphate signaling pathway (29). Inactivation of Akt, a key regulator of cell viability, is involved in degenerative diseases and stress-induced 
A

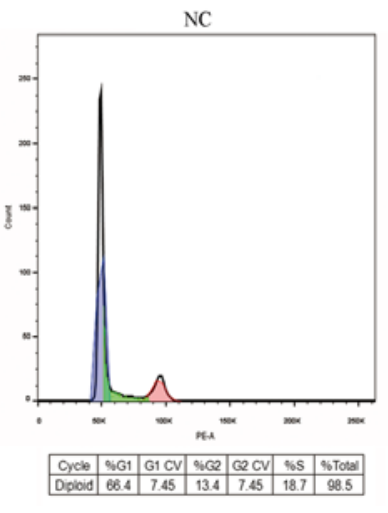

Betainel

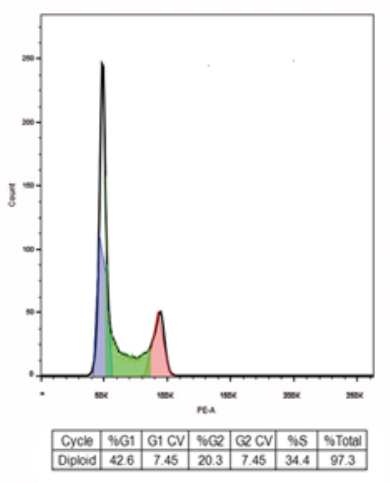

High glucose

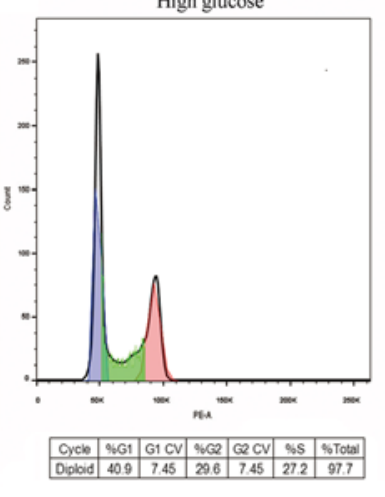

Betaine5

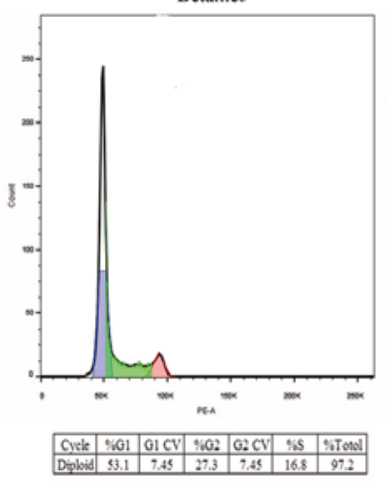

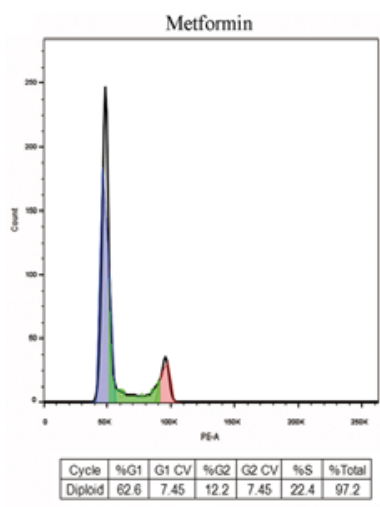

Betaine10

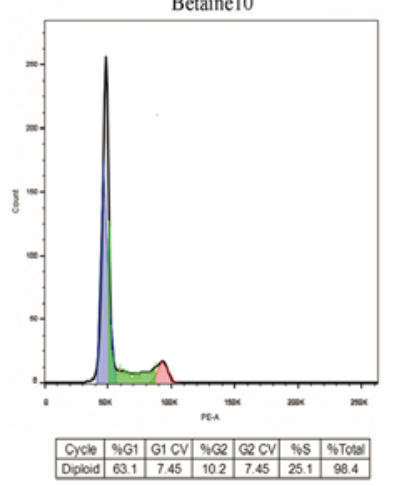

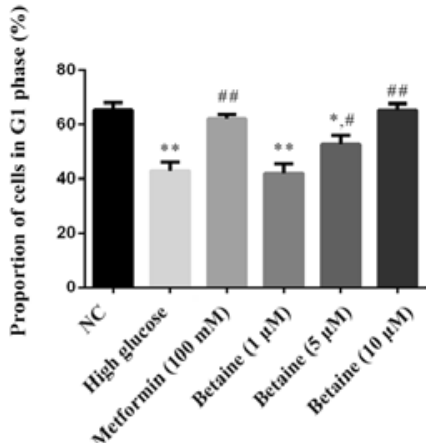

p $27^{\text {Kipl }}$
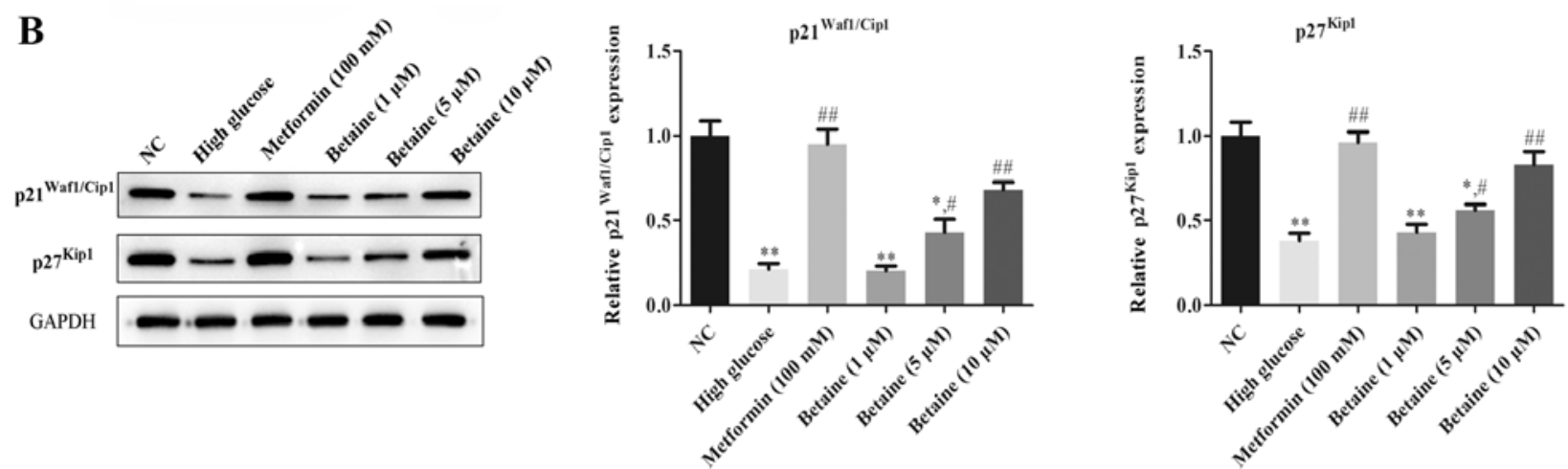

Figure 2. Betaine induces G1 phase arrest of MMCs. (A) Following treatment, the cell cycle distribution of MMCs was detected using flow cytometry and the proportion of cells in G1 phase was quantified. (B) Protein expression levels of p21 and p27 in different groups. Data were expressed as the mean \pm standard deviation. ${ }^{*} \mathrm{P}<0.05,{ }^{* *} \mathrm{P}<0.01$ vs. NC; ${ }^{\# \mathrm{P}}<0.05,{ }^{\# \#} \mathrm{P}<0.01$ vs. High glucose. MMCs, mouse mesangial cells; NC, negative control.

pathological cell death $(30,31)$. It has been reported that the Akt signaling pathway is associated with DN (29); an Akt inhibitor was able to attenuate HG-induced cell proliferation, inflammation and ECM expression in mesangial cells (32). Compounds such as daphnetin and zeaxanthin, could ameliorate $\mathrm{HG}$-induced mesangial cell apoptosis via the Akt signaling pathway $(32,33)$. Our results indicated that betaine inhibited MMC proliferation and ECM deposition via the Akt signaling pathway, which is in consistent with previous studies. The Erk1/2 signaling pathway is also involved in DN (34). Erk has been implicated in cell proliferation and differentiation, as it can induce the expression of certain genes (35). As mesangial cell proliferation is facilitated by the activation of Erk1/2, its inhibition protected mesangial cells under HG conditions by suppressing cell proliferation and ECM deposition $(36,37)$. In addition, p38 MAPK, which is associated with cell apoptosis initiation and cell cycle arrest, has been demonstrated to be activated in glomerular mesangial cells under HG conditions $(38,39)$. In the present study, it was demonstrated that Akt, Erk1/2 and p38 MAPK were activated in MMCs under HG conditions, and betaine was proposed to exert its protective effects via the Akt/Erk/p38 MAPK signaling pathway.

However, there are certain limitations to the present study. There are three isoforms of Akt in mammalian cells, namely Akt1, Akt2 and Akt3. Though it has been reported that Akt2 was strongly associated with the regulation of glucose homoeostasis and is the predominant Akt isoform expressed in insulin-responsive tissues (40), the specific binding sites for betaine on Akt were not determined. Additionally, the specific targets activated downstream of the Akt/Erk1/2/p38 MAPK signaling pathway should be investigated in subsequent studies. Furthermore, HG in culture cannot completely mimic diabetic conditions in vivo; experiments using diabetic 
A

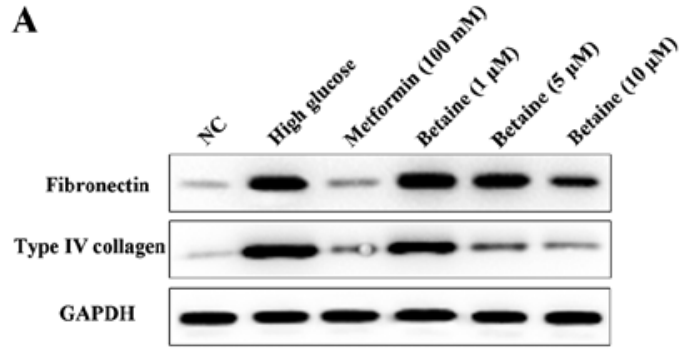

B

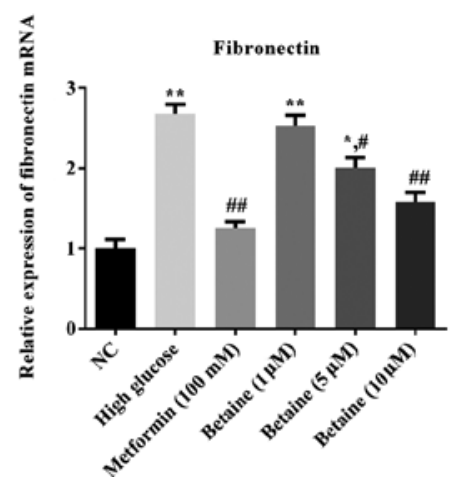

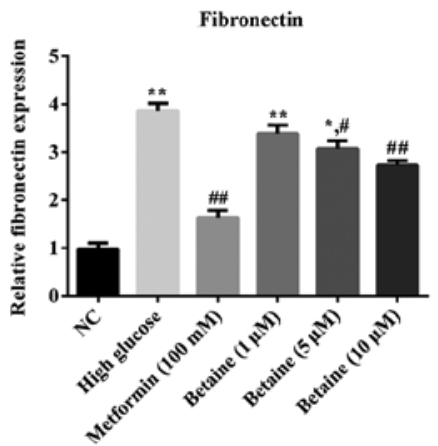
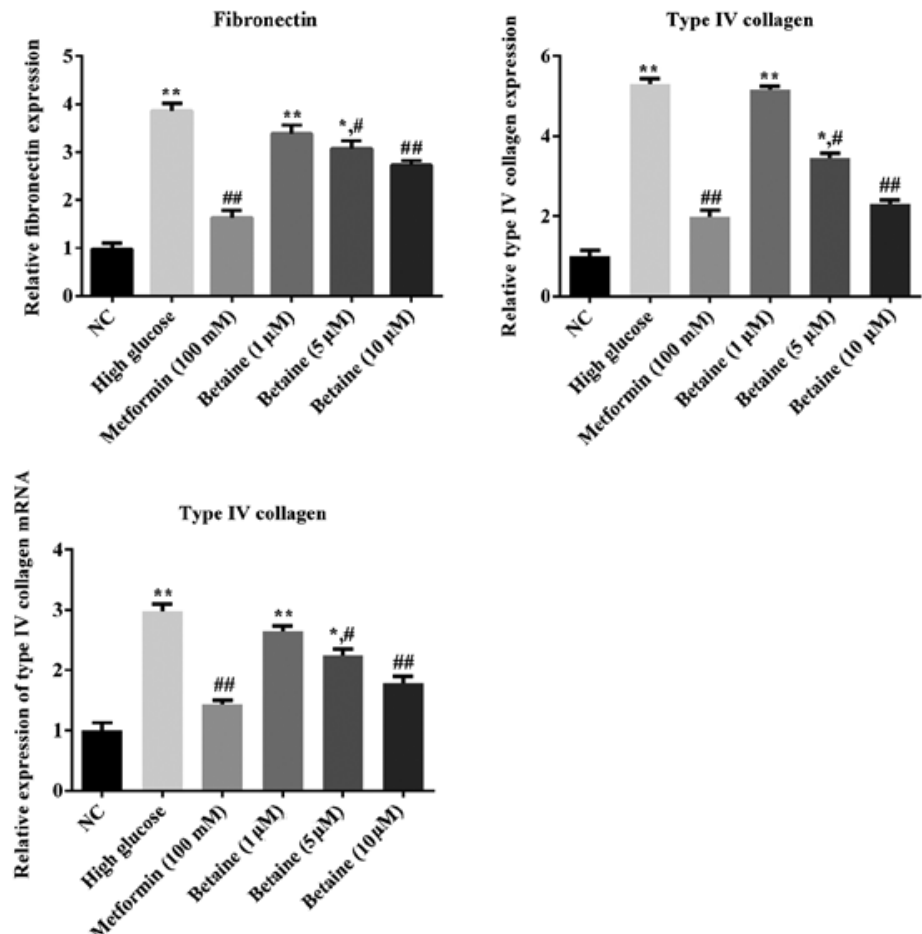

Figure 3. Betaine inhibits fibronectin and type IV collagen expression in mouse mesangial cells. Following treatment, the (A) protein and (B) mRNA expression levels of fibronectin and type IV collagen were detected using western blotting and reverse transcription-quantitative polymerase chain reaction, respectively. ${ }^{*} \mathrm{P}<0.05,{ }^{* *} \mathrm{P}<0.01$ vs. $\mathrm{NC} ;{ }^{\#} \mathrm{P}<0.05,{ }^{\# /} \mathrm{P}<0.01$ vs. High glucose. NC, negative control.
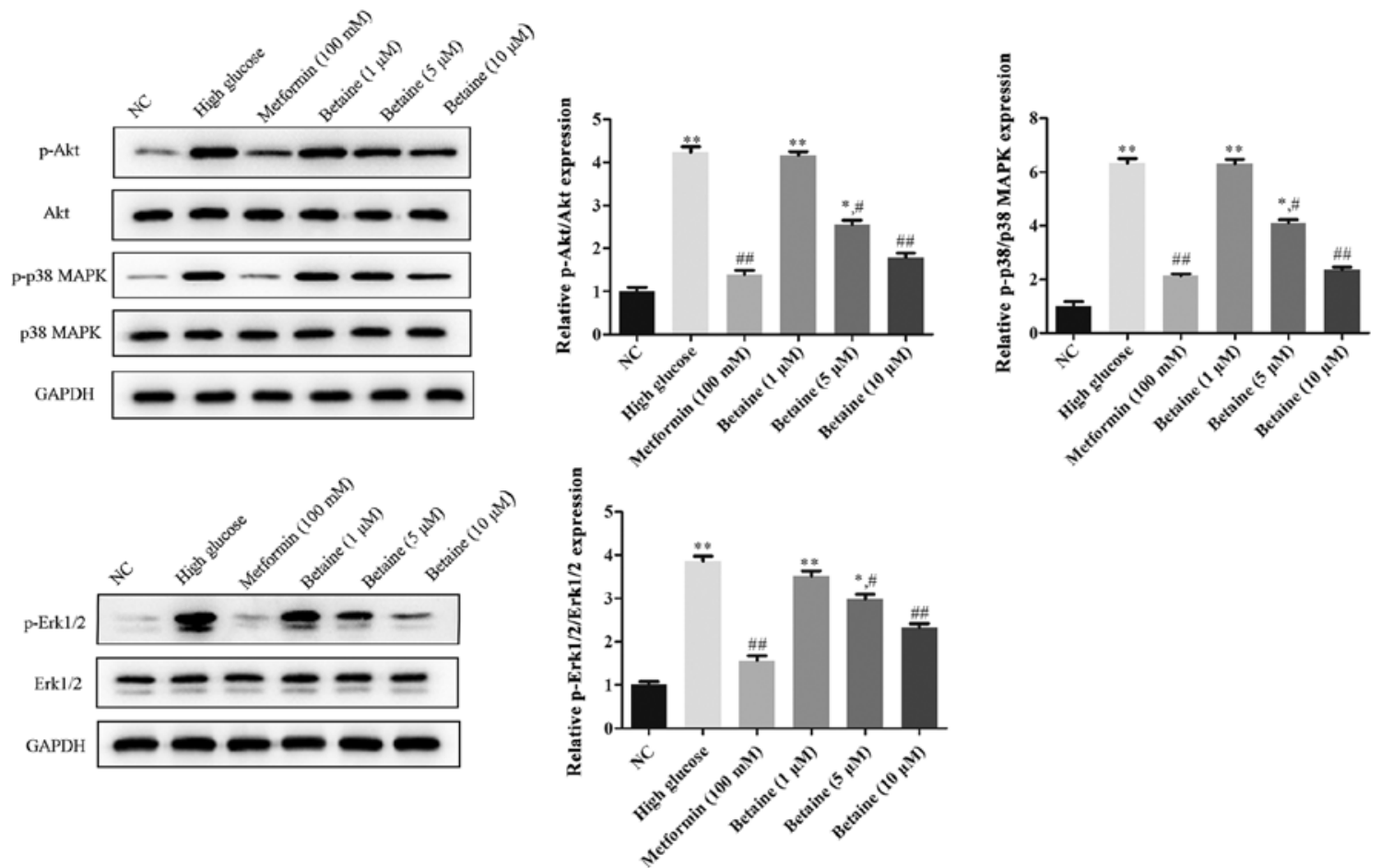

Figure 4. Effects of betaine on the activation of Akt, Erk1/2 and p38 in mouse mesangial cells. Following treatment, the protein expression levels of Akt, Erk1/2, p38 MAPK, p-AKT, p-Erk1/2 and p-p38 MAPK was measured via western blotting. ${ }^{~} \mathrm{P}<0.05,{ }^{* *} \mathrm{P}<0.01$ vs. NC; ${ }^{*} \mathrm{P}<0.05$, ${ }^{\# \#} \mathrm{P}<0.01$ vs. High glucose. AKT, protein kinase B; Erk, extracellular-signal-regulated kinase; MAPK, mitogen-activated protein kinase; NC, negative control; p, phosphorylated.

mouse models should be performed to validate these preliminary data. The present study reported the protective effects of betaine in vitro; the effects of betaine treatment in vivo should be determined in the future.
Collectively, the findings of the current study indicated that betaine exerted a protective effect on MMCs under HG conditions by inhibiting MMC proliferation and ECM deposition via regulation of the Akt/Erk1/2/p38 MAPK signaling pathway. 


\section{Acknowledgements}

Not applicable.

\section{Funding}

The present study was supported by The Clinical Evaluation of the Traditional Chinese and Western Medicine Research Project of Tianjin Municipal Health Bureau 'Clinical Evaluation of the Quantitative Effect Relationship of Pancreatic Live Dispersion in the Treatment of Type 2 Diabetes' (grant no. 07025).

\section{Availability of data and materials}

The analyzed data sets generated during the present study are available from the corresponding author on reasonable request.

\section{Authors' contributions}

XL made substantial contributions to the design of the present study. LW and HM performed the experiments. XL and HM analyzed the data. XL and LW wrote the manuscript. XL revised the manuscript. All authors reviewed the manuscript.

\section{Ethics approval and consent to participate}

The present study was approved by Institutional Animal Care and Use Committee of Tianjin Third Central Hospital and conducted in accordance with the National Institutes of Health Guide for the Care and Use of Laboratory Animals (14).

\section{Patient consent for publication}

Not applicable.

\section{Competing interests}

The authors declare that they have no competing interests.

\section{References}

1. Fineberg D, Jandeleit-Dahm KA and Cooper ME: Diabetic nephropathy: Diagnosis and treatment. Nat Rev Endocrinol 9: 713-723, 2013.

2. Jha V, Garcia-Garcia G, Iseki K, Li Z, Naicker S, Plattner B, Saran R, Wang AY and Yang CW: Chronic kidney disease: Global dimension and perspectives. Lancet 382: 260-272, 2013.

3. Gross JL, de Azevedo MJ, Silveiro SP, Canani LH, Caramori ML and Zelmanovitz T: Diabetic nephropathy: Diagnosis, prevention, and treatment. Diabetes Care 28: 164-176, 2005.

4. Liu L, Hu X, Cai GY,Lv Y,Zhuo L, Gao JJ, Cui SY, Feng Z, Fu B and Chen XM: High glucose-induced hypertrophy of mesangial cells is reversed by connexin 43 overexpression via PTEN/Akt/mTOR signaling. Nephrol Dial Transplant 27: 90-100, 2012.

5. Mason RM and Wahab NA: Extracellular matrix metabolism in diabetic nephropathy. J Am Soc Nephrol 14: 1358-1373, 2003.

6. Zhang J, Zhong HB, Lin Y, Yao W and Huang JY: KLF15 suppresses cell proliferation and extracellular matrix expression in mesangial cells under high glucose. Int J Clin Exp Med 8: 20330-20336, 2015.

7. Craig SA: Betaine in human nutrition. Am J Clin Nutr 80: 539-549, 2004.

8. Cabezón FA, Stewart KR, Schinckel AP, Barnes W, Boyd RD, Wilcock $\mathrm{P}$ and Woodliff J: Effect of natural betaine on estimates of semen quality in mature AI boars during summer heat stress. Anim Reprod Sci 170: 25-37, 2016.
9. Zhang F, Warskulat U and Häussinger D: Modulation of tumor necrosis factor-alpha release by anisoosmolarity and betaine in rat liver macrophages (Kupffer cells). FEBS Lett 391: 293-296, 1996.

10. Ganesan M, Zhang J, Bronich T, Poluektova L, Donohue TM Jr, Tuma DJ, Kharbanda KK and Osna NA: Acetaldehyde accelerates $\mathrm{HCV}$-induced impairment of innate immunity by suppressing methylation reactions in liver cells. Am J Physiol Gastrointest Liver Physiol 309: G566-G577, 2015.

11. Sillence MN: Technologies for the control of fat and lean deposition in livestock. Vet J 167: 242-257, 2004.

12. Schicho R, Shaykhutdinov R, Ngo J, Nazyrova A, Schneider C, Panaccione R, Kaplan GG, Vogel HJ and Storr M: Quantitative metabolomic profiling of serum, plasma, and urine by (1)H NMR spectroscopy discriminates between patients with inflammatory bowel disease and healthy individuals. J Proteome Res 11: 3344-3357, 2012.

13. Evran B, Aydın AF, Uğuralp B, Sar M, Doğru-Abbasoğlu S and Uysal M: Betaine treatment decreased serum glucose and lipid levels, hepatic and renal oxidative stress in streptozotocin-induced diabetic rats. Turk J Biochem 43, 2017.

14. Guide for the Care and Use of Laboratory Animals. Washington (DC): National Academies Press (US); 2011.

15. Kim YS, Reddy MA, Lanting L, Adler SG and Natarajan R: Differential behavior of mesangial cells derived from 12/15-lipoxygenase knockout mice relative to control mice. Kidney Int 64: 1702-1714, 2003.

16. Livak KJ and Schmittgen TD: Analysis of relative gene expression data using real-time quantitative PCR and the 2(-Delta Delta C(T)) method. Methods 25: 402-408, 2001.

17. He F, Xia X, Wu XF, Yu XQ and Huang FX: Diabetic retinopathy in predicting diabetic nephropathy in patients with type 2 diabetes and renal disease: A meta-analysis. Diabetologia 56: 457-466, 2013.

18. Schieppati A and Remuzzi G: Chronic renal diseases as a public health problem: Epidemiology, social, and economic implications. Kidney Int Suppl 98: S7-S10.2005.

19. Zhuo L, Zou G, Li W, Lu J and Ren W: Prevalence of diabetic nephropathy complicating non-diabetic renal disease among Chinese patients with type 2 diabetes mellitus. Eur J Med Res 18: 4, 2013.

20. Cholewa JM, Guimarães-Ferreira L and Zanchi NE: Effects of betaine on performance and body composition: A review of recent findings and potential mechanisms. Amino Acids 46: 1785-1793, 2014.

21. Hagar $\mathrm{H}$ and Al Malki W: Betaine supplementation protects against renal injury induced by cadmium intoxication in rats: Role of oxidative stress and caspase-3. Environ Toxicol Pharmacol 37: 803-811, 2014.

22. Ananth CV, Elsasser DA, Kinzler WL, Peltier MR, Getahun D, Leclerc D and Rozen RR; New Jersey Placental Abruption Study Investigators: Polymorphisms in methionine synthase reductase and betaine-homocysteine Smethyl-transferase genes: Risk of placental abruption. Mol Genet Metab 91: 104-110, 2007.

23. Kempson SA, Vovor-Dassu K and Day C: Betaine transport in kidney and liver: Use of betaine in liver injury. Cell Physiol Biochem 32: 32-40, 2013.

24. Bonig H, Daublin G, Schwahn B and Wendel U: Psychotic symptoms insevere MTHFR deficiency and their successful treatment with betaine. Eur J Pediatr 162: 200-201, 2003.

25. Patrick L: Nonalcoholic fatty liver disease: Relationship to insulin sensitivity and oxidative stress. Treatment approaches using vitamin E, magnesium, and betaine. Altern Med Rev 7: 276-291, 2002.

26. Hammer MA and Baltz JM: Betaine is a highly effective organic osmolyte but does not appear to be transported by established organic osmolyte transporters in mouse embryos. Mol Reprod Dev 62: 195-202.2002.

27. Abdelmalek MF, Angulo P, Jorgensen RA, Sylvestre PB and Lindor KD: Betaine, a nonalcoholic steatohepatitis: Results of a pilot promising new study. Am J Gastroenterol 96: 2711-2717, 2001.

28. Ma Y, Chen F, Yang S, Chen B and Shi J: Protocatechuic acid ameliorates high glucose-induced extracellular matrix accumulation in diabetic nephropathy. Biomed Pharmacother 98: 18-22, 2018.

29. Ying C, Mao Y, Chen L, Wang S, Ling H, Li W and Zhou X: Bamboo leaf extract ameliorates diabetic nephropathy through activating the AKT signaling pathway in rats. Int $\mathrm{J}$ Biol Macromol 105: 1587-1594, 2017. 
30. Zhang S, Chen X, Huang Z, Chen D, Yu B, Chen H, Luo J, He J, Zheng $\mathrm{P}$ and $\mathrm{Yu}$ J: Leucine promotes differentiation of porcine myoblasts through the protein kinase B (Akt)/Forkhead box O1 signalling pathway. Br J Nutr 119: 727-733, 2018.

31. Heath JM, Sun Y, Yuan K, Bradley WE, Litovsky S, Dell'Italia LJ, Chatham JC, Wu H and Chen Y: Activation of AKT by O-linked $\mathrm{N}$-acetylglucosamine induces vascular calcification in diabetes mellitus. Circ Res 114: 1094-1102, 2014.

32. Xu K, Guo L, Bu H and Wang H: Daphnetin inhibits high glucose-induced extracellular matrix accumulation, oxidative stress and inflammation in human glomerular mesangial cells. J Pharmacol Sci 139: 91-97, 2019.

33. Ying C, Chen L, Wang S, Mao Y, Ling H, Li W and Zhou X: Zeaxanthin ameliorates high glucose-induced mesangial cell apoptosis through inhibiting oxidative stress via activating AKT signaling-pathway. Biomed Pharmacother 90: 796-805, 2017.

34. Shang J, Zhang Y, Jiang Y, Li Z, Duan Y, Wang L, Xiao J and Zhao Z: NOD2 promotes endothelial-to-mesenchymal transition of glomerular endothelial cells via MEK/ERK signaling pathway in diabetic nephropathy. Biochem Biophys Res Commun 484: 435-441, 2017.

35. Flores K and Seger R: Stimulated nuclear import by $\beta$-like importins. F1000Prime Rep 5: 41, 2013.
36. Wang Y, Wang M, Chen B and Shi J: Scoparone attenuates high glucose-induced extracellular matrix accumulation in rat mesangial cells. Eur J Pharmacol 815: 376-380, 2017.

37. Suzaki Y, Yoshizumi M, Kagami S, Nishiyama A, Ozawa Y, Kyaw M, Izawa Y, Kanematsu Y, Tsuchiya K and Tamaki T: BMK1 is activated in glomeruli of diabetic rats and in mesangial cells by high glucose conditions. Kidney Int 65: 1749-1760, 2004.

38. Chen L, Mayer JA, Krisko TI, Speers CW, Wang T, Hilsenbeck SG and Brown PH: Inhibition of the p38 kinase suppresses the proliferation of human ER-negative breast cancer cells. Cancer Res 69: 8853-8861, 2009.

39. Goldberg H, Whiteside $\mathrm{C}$ and Fantus IG: O-linked $\beta$-N-acetylglucosamine supports p38 MAPK activation by high glucose in glomerular mesangial cells. Am J Physiol Endocrine Metab 301: E713-E726, 2011.

40. Dummler B and Hemmings BA: Physiological roles of PKB/Akt isoforms in development and disease. Biochem Soc Trans 35: 231-235, 2007.

This work is licensed under a Creative Commons Attribution-NonCommercial-NoDerivatives 4.0 International (CC BY-NC-ND 4.0) License. 